\title{
Cocoa butter equivalent from Kpangnan butter and Pequi oil
}

\author{
Saeed Mirzaee Ghazani ${ }^{1}$, Andrea Madalena Guedes², Rosemar Antoniassi ${ }^{2}$, and Alejandro \\ Marangoni $^{1}$ \\ ${ }^{1}$ University of Guelph \\ ${ }^{2}$ Embrapa Food Agroindustry
}

October 25, 2021

\begin{abstract}
Novel cocoa butter equivalents were designed using dry fractionated Pequi oil and solvent fractionated Kpangnan butter. Static crystallization of binary mixtures of these two fractions into the triclinic form ( $\beta 2$ ) was achieved after 12 days for all mixtures and after 4 days for the 80:20 w/w and 90:10 w/w fractionated Kpangnan:Pequi oil mixtures. Moreover, after 60 days of storage at $22 \mathrm{oC}$, all binary blends (except $100 \%$ fractionated pequi oil and $100 \%$ fractionated Kpangnan butter) were crystallized in the most stable triclinic crystal form $(\beta 1)$. Here we also discovered an unusual melting behavior for the fractionaled 30:70 $\mathrm{w} / \mathrm{w}$ and 20:80 w/w fractionated Kpangnan:Pequi oil mixtures, where after 4 days of static crystallization at room 22oC, these mixtures displayed higher than predicted melting points, $41.89 \mathrm{oC}$ and $33.32 \mathrm{oC}$, respectively. This suggested a faster kinetics of transformation to the triclinic $\beta 2$ form for those mixtures. Our results suggest that the 30:70 w/w fractionated Kpangnan:Pequi oil mixture with a melting point of $34 \mathrm{oC}$ after 60 days storage at $22 \mathrm{oC}$, a stable triclinic $\beta 2$ form, and a triglyceride composition of $28 \%$ POP, $4.6 \%$ POS and $33 \%$ SOS displayed solid state characteristics, melting point and crystal structure, of a commercial cocoa butter equivalent.
\end{abstract}

\section{INTRODUCTION}

Exotic fats are defined as a group of fats obtained from wild, uncultivated crops. Common exotic butters such as illipe (Shorea stenoptera), sal (Shorea robusta), shea (Butyrospermum parkii), kokum (Garcinia indica), and mango kernel (Magnifera indica) have been used to manufacture CBE on an industrial scale. However, their supply on a large scale is limited since they are extracted from the seeds or kernels of wild fruit trees growing in tropical forests (Salas, Bootello, Martínez-Force, \& Garcés, 2009). The main triacylglycerols in these fats are either 1,3-stearoyl-2-oleoyl-glycerol (SOS) or a combination of 1-palmitoyl-2-oleoyl-3-stearoylglycerol (POS) and SOS, and these natural butters lack one of the main structural triacylglycerols (TAGs) of cocoa butter, 1,3-dipalmitoyl-2-oleoyl-glycerol (POP). The main source of POP for the formulation of commercial CBEs is palm-mid fraction (PMF) that is obtained by the multi-step dry fractionation of palm oil. Currently, the main concern about using palm oil and its derivatives in food is the lack of sustainability of these products as a result of rainforest destruction (Austin, Mosnier, Pirker, McCallum, Fritz, \& Kasibhatla, 2017). Although sustainable palm oil production has been started in some countries, these attempts are limited compared to total world palm oil production (Carlson, Heilmayr, Gibbs, Noojipady, Burns, Morton, Walker, Paoli, \& Kremen, 2018).

Pequi is a yellow to orange, strong-flavored oleaginous fruit of pequi tree (Caryocar brasiliense), mainly native of the Amazon, Caatinga, Cerrado, and the rainforest regions of Brazil. However, pequi trees can also be found in Central and South America (Guedes, Antoniassi \& Faria-Machado, 2017; Vieira \& Martins, 2000). Pequi fruit has a green spherical shape containing four internal yellowish mesocarps rich in oil (35-66\% dry base) covering four pequi kernels containing pequi kernel oil. Pequi kernel oil has non-edible applications in the oleochemical industry (Faria-Machado, Tres, van Ruth, Antoniassi, Junqueira, Lopes, \& Bizzo, 2015). 
Previous studies showed the primary fatty acids in pulp pequi oil were palmitic acid (36\%), palmitoleic acid $(1 \%)$, stearic acid $(2 \%)$, oleic acid $(57 \%)$, linoleic acid $(2 \%)$, and linolenic acid $(<0.5 \%)$. In comparison, the main TAGs in pequi oil were 1-palmitoyl-2 3-dioleoyl-glycerol (POO) (39\%) and POP (34\%) (Guedes, Antoniassi, Galdeano, Grimaldi, de Carvalho, Wilhelm \& Marangoni, 2017).

Kpangnan (Pentadesma butyracea) butter is also known as Kanga, Kanya, Painya, and Akpoto is obtained from the kernels of the berries that grow on the Kpangnan tree is known as tallow tree, predominantly in Ghana and some parts of West Africa such as Democratic Republic of Congo (Ayegnon, Kayodé, Tchobo, Azokpota, Soumanou \& Hounhouigan, 2015). Kpangnan butter has non-edible applications in African societies, and it is mainly used as a massage oil for skin and hair care and in the manufacturing of soap (Dencausse, Ntsourankoua, Artaud \& CLAMOU, 1995). The fatty acid composition of Kpangnan butter is quite similar to shea butter and mainly contains palmitic acid (3-4\%), stearic acid (43-47\%), oleic acid $(49-53 \%)$, and linoleic acid $(<1 \%)$. The main identified TAGs in Kpangnan butter are POS (1-2\%), triolein (OOO) (1.5-3\%), 1-stearoyl-2, 3-dioleoyl-glycerol (SOO) (35-49\%) and SOS (37-61\%). (Adomako, 1977; Tchobo, Natta, Barea, Barouh, Piombo, Pina, et al. \& Sohounhloue, 2007).

The main objective of this study was to evaluate the physicochemical properties of various mixtures of dry fractionated pequi oil as a source of POP and solvent fractionated Kpangnan butter as a source of SOS to produce more sustainable CBEs.

\section{Material and Methods}

Unrefined artisanal pequi pulp oil was provided by Fazenda Lagoa (Minas Gerais, Brazil), and Kpangnan butter was bought from ALAFFIA Co. (Olympia, WA, USA). Acetone (ACS reagent, > 99.5\%) for solvent crystallization was supplied from Fisher Scientific (Ottawa, ON, Canada).

\section{Pequi oil dry fractionation}

The pequi oil was dry fractionated in a 2L jacketed glass reactor (HEL D-95 126 Shwabach) with a paddletype mechanical stirrer connected to a high torque RZR 2102 motor (Heidolph Instruments, Schwabach, Germany) and a thermostatic bath (Julabo F25) with a temperature controller and thermocouples. First, 1000 to $1500 \mathrm{~g}$ of filtered oil was heated to $50^{\circ} \mathrm{C}$ for 20 minutes while mixing at $7 \mathrm{rpm}$, then it was cooled down at the rate of $3^{\circ} \mathrm{C} / \mathrm{h}$ to the crystallization temperature $\left(20^{\circ} \mathrm{C}\right)$, and while mixing was continued it was kept at $20^{\circ} \mathrm{C}$ for seven hours. The olein fraction was gravimetric transferred to a jacketed stainless steel filtration system (Zeitz Enzinger NOLL Maschinenbau Maschinenbau AG EF1412, Mannheim, Germany) coupled to a vacuum pump (Prismatec, São Paulo, Brazil). The oleic fraction separation was repeated several times using filter paper (Unifil Qualitativo, C41) to obtain the stearin fraction.

\section{Kpangnan butter solvent fractionation}

Acetone fractionation was used to remove high melting and low melting TAGs from the Kpangnan oil to obtain a higher proportion of SOS in the final fractions. The ratio of Kpangnan oil: acetone was 1:4 w/w to fractionate at three different temperatures of 16,22 , and $25{ }^{\circ} \mathrm{C}$. In the first acetone crystallization step, most of the SOS was fractionated, while the second and the third fractionations were used to remove low melting TAGs (SOO and OOO) and increasing SOS concentration.

\section{Preparing binary mixtures}

Binary mixtures were prepared by mixing melted pequi stearin (FPO) (obtained by dry fractionation at $20 \mathrm{C}^{\circ}$ ) with fractionated Kpagnan butter (FKB) in the ratios of 0:100, 10:90, 20:80, 30:70, 40:60, 50:50, $60: 40,70: 30,80: 20,90: 10$, and 100:0 (w/w). The mixtures were heated to $80^{\circ} \mathrm{C}$ for 30 minutes to clear the memory of crystallization then solidified at room temperature $\left(22^{\circ} \mathrm{C}\right)$ for 4,12 , and 60 days under static crystallization, followed by XRD and DSC analysis.

\section{Determination of Triacylglycerol Composition}

The Triacylglycerol (TAG) composition of the fractionated pequi oil, fractionated Kpangnan butter, and 
their binary mixtures were determined using a Waters Alliance model 2690 high-performance liquid chromatography (HPLC) with a refractive index detector (Waters model 2410, Waters, Milford, MA, USA). Chromatographic separation of the TAGs in the samples was obtained with a Waters Xbridge C18 (Waters Limited, Mississauga, ON, Canada) column (4.6 $\mathrm{mm} \times 250 \mathrm{~mm}$ internal diameter with $5 \mu \mathrm{m}$ particle size). Isocratic elution with a flow rate of $1 \mathrm{mLmin}-1$ of degassed acetone/acetonitrile 60/40 (v/v) was applied. Column and detector temperatures were set at $40^{\circ} \mathrm{C}$. The separated peaks were analyzed using Millenium 32 software (K\&K Testing, LLC, Decatur, GA, USA). The TAG composition was determined using internal standards and their corresponding retention times.

\section{Crystal structure and polymorphism}

Static crystallization at room temperature $22-23^{\circ} \mathrm{C}$ at different crystallization times $(4,12$, and 60 days) was applied to crystallize blends before X-ray analysis. The crystal structure and polymorphic form of solidified samples were analyzed by X-ray diffraction (Multiflex Powder X-ray spectrometer, Rigaku, Tokyo, Japan). The copper X-ray tube (wavelength of $1.54 \AA$ ) was operated at $40 \mathrm{kV}$ and $44 \mathrm{~mA}$. The measurement scan rate was set at 0.3 per minute in the range $2 \vartheta=1-30$ at $20{ }^{\circ} \mathrm{C}$. The diffracted peak positions were determined using MDI Jade 9 (MDI, Livermore, CA, USA) software.

\section{Melting point and enthalpy of fusion}

Melting points and enthalpies of fusion of samples were obtained using a differential scanning calorimeter (DSC) model Q2000 (TA Instruments, Mississauga, ON, Canada). Nitrogen was used as the purge gas with a flow of $18 \mathrm{~mL} /$ minute. In this experiment, melting points (endothermic peak) of samples $(2-5 \mathrm{mg})$ were determined by heating samples from $5{ }^{\circ} \mathrm{C}$ to $60{ }^{\circ} \mathrm{C}$ at the heating rate of $5{ }^{\circ} \mathrm{C} /$ minute.

\section{RESULTS AND DISCUSSION}

Crystal structure and polymorphism

Binary mixtures of dry fractionated pequi oil (source of POP) and solvent fractionated Kpangnan butter (source of SOS) were prepared at different proportions and kept at room temperature to statically crystallize them for 4, 12, and 60 days. In a previous study, we showed that a CBE's compatibility with CB depends on the main triacylglycerols present in the CBE and their crystal polymorphic structure. This is mostly influenced by interactions between the main TAGs in CBE and CB, namely POP, POS, and SOS (Ghazani \& Marangoni, 2018). Small and wide-angle powder X-ray diffraction peaks after 4, 12, and 60 days of storage at room temperature are shown in Tables 1 to 3, respectively. As shown in Table 1 and Fig.1, the most prominent reflections in the WAXS region for $100 \%$ solvent fractionated Kpangnan butter were observed at $4.74 \AA(\mathrm{s}), 4.50 \AA(\mathrm{m}), 3.9 \AA(\mathrm{S})$, and $3.63 \AA(\mathrm{w})$, suggesting the $\gamma$ crystal structure of SOS (Sato, Arishima, Wang, Ojima, Sagi \& Mori, 1989). In this field, vs, s, m, and w, represent "very strong", "strong", "medium" and "weak" peak intensities. The long-spacing observed for $100 \%$ fractionated Kpangnan butter was at 73.7 $\AA$, corresponding to the reflection from the (001) crystalline plane.

Similar short-spacing has been reported by Sato, Arishima, Wang, Ojima, Sagi \& Mori (1989) for SOS in $\gamma$ crystal form at $4.72 \AA(\mathrm{s}), 4.50 \AA(\mathrm{m}), 3.88 \AA(\mathrm{s})$, and $3.63 \AA(\mathrm{w})$, while Wang, Sato, Sagi, Izumi \& Mori (1987) reported an identical long-spacing pattern at $73.7 \AA$ for SOS in $\gamma$ crystal form. Similar diffraction patterns in both SAXS and WAXS regions were observed for 10\% to $40 \%$ mixtures containing fractionated pequi oil. With increasing amounts of fractionated pequi oil, from $50 \%$ to $70 \%$, a mixture of $\gamma$ and pseudo- $\beta_{2}{ }_{2}$ polymorphic forms was obtained. This can be deduced from the presence of a reflection at ${ }^{\sim} 42 \AA$ in the SAXS region and WAXS reflections at $4.23 \AA$ and $3.96 \AA$ that indicates the presence of the pseudo- $\beta$ ' ${ }_{2}$ form of POP (Sato, Arishima, Wang, Ojima, Sagi \& Mori, 1989). Moreover, the long-spacing value at $42 \AA$ corresponds to the double chain length structure of the POP molecule in the pseudo- $\beta$ ' ${ }_{2}$ crystal structure (Sato, Arishima, Wang, Ojima, Sagi \& Mori, (1989). The binary mixtures containing $80 \%$ and $90 \%$ fractionated pequi oil showed a mixture of mainly triclinic crystal structures in the $\beta_{2}$ crystal form plus pseudo- $\beta_{2}{ }_{2}$ form. After static crystallization at room temperature for four days, $100 \%$ fractionated pequi oil showed a pseudo- $\beta^{\prime}{ }_{2}$ crystal structure. 
After 12 days of storage at $22{ }^{\circ} \mathrm{C}$, in all mixtures, the pseudo- $\beta_{2}{ }_{2}$ form had transformed to the stable triclinic $\beta_{2}$ form, except for $100 \%$ fractioned pequi oil and $100 \%$ fractionated Kpangnan butter, which displayed the pseudo- $\beta_{2}{ }_{2}$ form, and mixtures of pseudo- $\beta_{2}{ }_{2}$ and $\beta_{2}$ crystal forms, respectively. A double chain length structure characteristic of the pseudo- $\beta{ }_{2}$ form was observed in both samples (Table 2 and Fig.1).

After 60 days of storage at $22{ }^{\circ} \mathrm{C}$, all mixtures had transformed to the triclinic $\beta_{2}$ form, except for $100 \%$ fractionated pequi oil. Two strong reflections in the WAXS region at $4.30 \AA$ and $3.97 \AA$, and a long spacing of $41.9 \AA$ were observed (Table 3 ). This suggested the presence of a pseudo- $\beta{ }^{\prime}{ }_{1}$ polymorphic form, similar to the crystal polymorphic form of pure POP in the pseudo- $\beta{ }_{1}{ }_{1}$ crystal form (Sato, Ueno \& Yano1999). Wang, Sato, Sagi, Izumi \& Mori (1987) showed that the polymorphic transition rate for the POP molecule was very slow, and the transition from pseudo- $\beta^{\prime}$ to $\beta_{2}$ took about 15 days after storing at $30^{\circ} \mathrm{C}$. While for SOS molecule, the transition rate from pseudo- $\beta$ ' to $\beta_{2}$ was fast $\left(16\right.$ hours at $\left.35^{\circ} \mathrm{C}\right)$.

The addition of fractionated Kpangnan butter to fractionated pequi oil accelerated the crystal polymorphic transition to the triclinic form. The very strong peak at $4.6 \AA$ indicated the $\beta$ crystal structure for all blends. It is important to notice that after 60-days of storage, the high SOS content in fractionated Kpangnan butter induced a transformation to the $\beta_{1}$ polymorphic form for all mixtures. The presence of two strong peaks at $3.73 \AA$ and $3.69 \AA$ indicated the completion of the polymorphic transition to the most stable triclinic form $\left(\beta_{1}\right)$ (Fig. 2). Sato, Arishima, Wang, Ojima, Sagi \& Mori (1989) reported a similar diffraction pattern for pure SOS in the $\beta_{1}$ crystal form.

Table 1- Small and wide-angle powder X-ray diffraction data for the different crystal polymorphic forms of fractionated pequi oil and fractionated Kpangnan butter binary mixtures after 4 days of storage

\begin{tabular}{|c|c|c|c|c|c|c|c|}
\hline $\begin{array}{l}\text { Fractionated } \\
\text { Pequi oil } \\
(\%)\end{array}$ & $\begin{array}{l}\text { Long- } \\
\text { spacing } \\
(\AA)\end{array}$ & $\begin{array}{l}\text { Short- } \\
\text { spacing } \\
(\AA)^{*}\end{array}$ & $\begin{array}{l}\text { Short- } \\
\text { spacing } \\
(\AA)^{*}\end{array}$ & $\begin{array}{l}\text { Short- } \\
\text { spacing } \\
(\AA)^{*}\end{array}$ & $\begin{array}{l}\text { Short- } \\
\text { spacing } \\
(\AA)^{*}\end{array}$ & $\begin{array}{l}\text { Short- } \\
\text { spacing } \\
(\AA)^{*}\end{array}$ & $\begin{array}{l}\text { Short- } \\
\text { spacing } \\
(\AA)^{*}\end{array}$ \\
\hline $0(\gamma)$ & 73.7 & $4.74(\mathrm{~s})$ & $4.50(\mathrm{~m})$ & $3.90(\mathrm{~s})$ & $3.63(\mathrm{w})$ & - & - \\
\hline $10(\gamma)$ & 70.1 & $4.74(\mathrm{~s})$ & $4.55(\mathrm{~m})$ & $4.46(\mathrm{~m})$ & $4.21(\mathrm{w})$ & $3.90(\mathrm{~s})$ & $3.60(\mathrm{w})$ \\
\hline $20(\gamma)$ & 70.1 & $4.74(\mathrm{~s})$ & $4.57(\mathrm{~m})$ & $4.43(\mathrm{~m})$ & $4.21(\mathrm{w})$ & $3.90(\mathrm{~s})$ & $3.62(\mathrm{w})$ \\
\hline $\begin{array}{l}30(\gamma+ \\
\left.\text { pseudo- } \beta_{2}{ }_{2}\right)\end{array}$ & 71.8 & $4.77(\mathrm{~s})$ & $4.58(\mathrm{~m})$ & $4.46(\mathrm{~m})$ & $4.23(\mathrm{w})$ & $3.92(\mathrm{~s})$ & $3.60(\mathrm{w})$ \\
\hline $\begin{array}{l}40(\gamma+ \\
\left.\text { pseudo- } \beta{ }_{2}\right)\end{array}$ & 71.3 & $4.77(\mathrm{~s})$ & $4.57(\mathrm{~m})$ & $4.48(\mathrm{~m})$ & $4.23(\mathrm{w})$ & $3.91(\mathrm{~s})$ & $3.60(\mathrm{w})$ \\
\hline $\begin{array}{l}50(\gamma+ \\
\left.\text { pseudo- } \beta_{2}{ }_{2}\right)\end{array}$ & $\begin{array}{l}42.2 \text { and } \\
70.1\end{array}$ & $4.74(\mathrm{~m})$ & $4.57(\mathrm{~m})$ & $4.43(\mathrm{~m})$ & $4.21(\mathrm{~m})$ & $3.98(\mathrm{~m})$ & $3.90(\mathrm{~s})$ \\
\hline $\begin{array}{l}60(\gamma+ \\
\left.\text { pseudo- } \beta{ }_{2}\right)\end{array}$ & $\begin{array}{l}42.6 \text { and } \\
70.1\end{array}$ & $4.76(\mathrm{~m})$ & $4.59(\mathrm{~m})$ & $4.43(\mathrm{~m})$ & $4.21(\mathrm{~m})$ & $3.98(\mathrm{~s})$ & $3.90(\mathrm{~m})$ \\
\hline $\begin{array}{l}70(\gamma+ \\
\left.\text { pseudo- } \beta^{\prime}{ }_{2}\right)\end{array}$ & $\begin{array}{l}41.4 \text { and } \\
69.8\end{array}$ & $4.75(\mathrm{~m})$ & $4.58(\mathrm{~m})$ & $4.42(\mathrm{~m})$ & $4.21(\mathrm{~m})$ & $3.97(\mathrm{vs})$ & $3.90(\mathrm{~m})$ \\
\hline $80\left(\beta_{2}\right)$ & $\begin{array}{l}41.8 \text { and } \\
61.0\end{array}$ & $4.57(\mathrm{vs})$ & $4.04(\mathrm{~m})$ & $3.97(\mathrm{~m})$ & $3.87(\mathrm{~m})$ & $3.71(\mathrm{~m})$ & - \\
\hline $90\left(\beta_{2}\right)$ & $\begin{array}{l}40.9 \text { and } \\
61.8\end{array}$ & $4.58(\mathrm{vs})$ & $4.06(\mathrm{~m})$ & $3.97(\mathrm{~m})$ & $3.88(\mathrm{~m})$ & $3.73(\mathrm{~m})$ & - \\
\hline $\begin{array}{l}100 \\
\left(\text { pseudo- } \beta{ }_{2}\right)\end{array}$ & 41.6 & $4.59(\mathrm{~m})$ & $4.27(\mathrm{~s})$ & $3.97(\mathrm{~s})$ & - & - & - \\
\hline
\end{tabular}

*vs, s, m, and w represent "very strong", "strong", "medium" and "weak" peak intensities.

Table 2- Small and wide-angle powder X-ray diffraction data for the different crystal polymorphic forms of fractionated pequi oil and Kpangnan butter binary mixtures after 12 days of storage 


\begin{tabular}{|c|c|c|c|c|c|c|c|}
\hline $\begin{array}{l}\text { Fractionated } \\
\text { Pequi oil } \\
(\%)\end{array}$ & $\begin{array}{l}\text { Long- } \\
\text { spacing } \\
(\AA)\end{array}$ & $\begin{array}{l}\text { Short- } \\
\text { spacing } \\
(\AA)^{*}\end{array}$ & $\begin{array}{l}\text { Short- } \\
\text { spacing } \\
(\AA)^{*}\end{array}$ & $\begin{array}{l}\text { Short- } \\
\text { spacing } \\
(\AA)^{*}\end{array}$ & $\begin{array}{l}\text { Short- } \\
\text { spacing } \\
(\AA)^{*}\end{array}$ & $\begin{array}{l}\text { Short- } \\
\text { spacing } \\
(\AA)^{*}\end{array}$ & $\begin{array}{l}\text { Short- } \\
\text { spacing } \\
(\AA)^{*}\end{array}$ \\
\hline $\begin{array}{l}0 \\
\left(\text { pseudo- } \beta{ }_{2}{ }_{2}\right)\end{array}$ & $\begin{array}{l}65.1 \text { and } \\
74.0\end{array}$ & $4.74(\mathrm{vs})$ & $4.59(\mathrm{~s})$ & $4.49(\mathrm{~m})$ & 3.9 (vs) & $3.67(\mathrm{~m})$ & $3.61(\mathrm{~m})$ \\
\hline $10\left(\beta_{2}\right)$ & 64.3 & 4.59 (vs) & $4.29(\mathrm{~m})$ & $4.04(\mathrm{~m})$ & $3.88(\mathrm{~m})$ & $3.70(\mathrm{~m})$ & - \\
\hline $20\left(\beta_{2}\right)$ & 64.5 & 4.61 (vs) & $4.30(\mathrm{~m})$ & $4.04(\mathrm{~m})$ & $3.88(\mathrm{~m})$ & $3.70(\mathrm{~m})$ & - \\
\hline $30\left(\beta_{2}\right)$ & 65.3 & $4.62(\mathrm{vs})$ & $4.29(\mathrm{~m})$ & $4.06(\mathrm{~m})$ & $3.91(\mathrm{~m})$ & $3.71(\mathrm{~m})$ & - \\
\hline $40\left(\beta_{2}\right)$ & 64.8 & $4.60(\mathrm{vs})$ & $4.27(\mathrm{w})$ & $4.04(\mathrm{~m})$ & $3.90(\mathrm{~m})$ & $3.71(\mathrm{~m})$ & - \\
\hline $50\left(\beta_{2}\right)$ & 63.6 & $4.58(\mathrm{vs})$ & $4.25(\mathrm{w})$ & $4.03(\mathrm{~m})$ & $3.88(\mathrm{~m})$ & $3.69(\mathrm{~m})$ & - \\
\hline $60\left(\beta_{2}\right)$ & 63.7 & 4.59 (vs) & $4.29(\mathrm{w})$ & $4.04(\mathrm{~m})$ & $3.88(\mathrm{~m})$ & $3.71(\mathrm{~m})$ & - \\
\hline $70\left(\beta_{2}\right)$ & 62.9 & $4.57(\mathrm{vs})$ & $4.27(\mathrm{w})$ & $4.02(\mathrm{~m})$ & $3.86(\mathrm{~m})$ & $3.69(\mathrm{~m})$ & - \\
\hline $80\left(\beta_{2}\right)$ & 62.4 & $4.57(\mathrm{vs})$ & $4.26(\mathrm{w})$ & $4.04(\mathrm{~m})$ & $3.84(\mathrm{~m})$ & $3.70(\mathrm{~m})$ & - \\
\hline $90\left(\beta_{2}\right)$ & 62.3 & $4.58(\mathrm{vs})$ & $4.26(\mathrm{w})$ & $4.05(\mathrm{~m})$ & $3.88(\mathrm{~m})$ & $3.70(\mathrm{~m})$ & - \\
\hline $\begin{array}{l}100 \\
\text { (pseudo- } \beta_{1}{ }_{1} \\
\left.+\beta_{2}\right)\end{array}$ & 40.0 & $4.57(\mathrm{~s})$ & $4.27(\mathrm{~s})$ & $4.16(\mathrm{w})$ & $3.95(\mathrm{~s})$ & $3.73(\mathrm{~m})$ & - \\
\hline
\end{tabular}

*vs, s, m, and w represent "very strong", "strong", "medium" and "weak" peak intensities.

Table 3- Small and wide-angle powder X-ray diffraction data for the different crystal polymorphic forms of fractionated pequi oil and Kpangnan butter binary mixtures after 60 days of storage

\begin{tabular}{llllllll}
\hline $\begin{array}{l}\text { Fractionated } \\
\text { Pequi oil } \\
(\%)\end{array}$ & $\begin{array}{l}\text { Long- } \\
\text { spacing } \\
(\AA)\end{array}$ & $\begin{array}{l}\text { Short- } \\
\text { spacing } \\
(\AA)^{*}\end{array}$ & $\begin{array}{l}\text { Short- } \\
\text { spacing } \\
(\AA)^{*}\end{array}$ & $\begin{array}{l}\text { Short- } \\
\text { spacing } \\
(\AA)^{*}\end{array}$ & $\begin{array}{l}\text { Short- } \\
\text { spacing } \\
(\AA) *\end{array}$ & $\begin{array}{l}\text { Short- } \\
\text { spacing } \\
(\AA)^{*}\end{array}$ & $\begin{array}{l}\text { Short- } \\
\text { spacing } \\
(\AA) *\end{array}$ \\
\hline $0\left(\beta_{2}\right)$ & 65.1 & $4.60(\mathrm{vs})$ & $4.01(\mathrm{~m})$ & $3.89(\mathrm{~m})$ & $3.78(\mathrm{~m})$ & $3.69(\mathrm{~m})$ & $3.58(\mathrm{w})$ \\
$10\left(\beta_{1}\right)$ & 64.9 & $4.58(\mathrm{vs})$ & $4.01(\mathrm{~m})$ & $3.89(\mathrm{~m})$ & $3.73(\mathrm{~s})$ & $3.69(\mathrm{~s})$ & $3.59(\mathrm{w})$ \\
$20\left(\beta_{1}\right)$ & 64.7 & $4.59(\mathrm{vs})$ & $4.06(\mathrm{~m})$ & $3.90(\mathrm{~m})$ & $3.72(\mathrm{~s})$ & $3.69(\mathrm{~s})$ & $3.59(\mathrm{w})$ \\
$30\left(\beta_{1}\right)$ & 64.1 & $4.57(\mathrm{vs})$ & $4.03(\mathrm{~m})$ & $3.89(\mathrm{~m})$ & $3.72(\mathrm{~s})$ & $3.68(\mathrm{~s})$ & $3.58(\mathrm{~m})$ \\
$40\left(\beta_{1}\right)$ & 64.6 & $4.59(\mathrm{vs})$ & $4.05(\mathrm{~m})$ & $3.90(\mathrm{~m})$ & $3.74(\mathrm{~s})$ & $3.69(\mathrm{~s})$ & $3.58(\mathrm{~m})$ \\
$50\left(\beta_{1}\right)$ & 63.8 & $4.58(\mathrm{vs})$ & $4.04(\mathrm{~m})$ & $3.88(\mathrm{~m})$ & $3.73(\mathrm{~s})$ & $3.68(\mathrm{~s})$ & $3.56(\mathrm{~m})$ \\
$60\left(\beta_{1}\right)$ & 63.7 & $4.59(\mathrm{vs})$ & $4.03(\mathrm{~m})$ & $3.87(\mathrm{~m})$ & $3.74(\mathrm{~s})$ & $3.69(\mathrm{~s})$ & $3.56(\mathrm{~m})$ \\
$70\left(\beta_{1}\right)$ & 63.3 & $4.60(\mathrm{vs})$ & $4.04(\mathrm{~m})$ & $3.86(\mathrm{~m})$ & $3.75(\mathrm{~s})$ & $3.70(\mathrm{~s})$ & $3.56(\mathrm{~m})$ \\
$80\left(\beta_{1}\right)$ & 62.9 & $4.59(\mathrm{vs})$ & $4.05(\mathrm{~m})$ & $3.86(\mathrm{~m})$ & $3.74(\mathrm{~s})$ & $3.69(\mathrm{~s})$ & $3.56(\mathrm{~m})$ \\
$90\left(\beta_{1}\right)$ & 61.4 & $4.57(\mathrm{vs})$ & $4.07(\mathrm{~m})$ & $3.85(\mathrm{~m})$ & $3.73(\mathrm{~s})$ & $3.69(\mathrm{~s})$ & $3.56(\mathrm{~m})$ \\
100 & 41.9 & $4.30(\mathrm{~s})$ & $4.21(\mathrm{~m})$ & $4.15(\mathrm{~m})$ & $3.97(\mathrm{vs})$ & $3.51(\mathrm{w})$ & - \\
$\left(\mathrm{pseudo-}{ }^{\prime}{ }_{1}\right)$ & & & & & & & \\
\hline
\end{tabular}

*vs, s, m, and w represent "very strong", "strong", "medium" and "weak" peak intensities. 

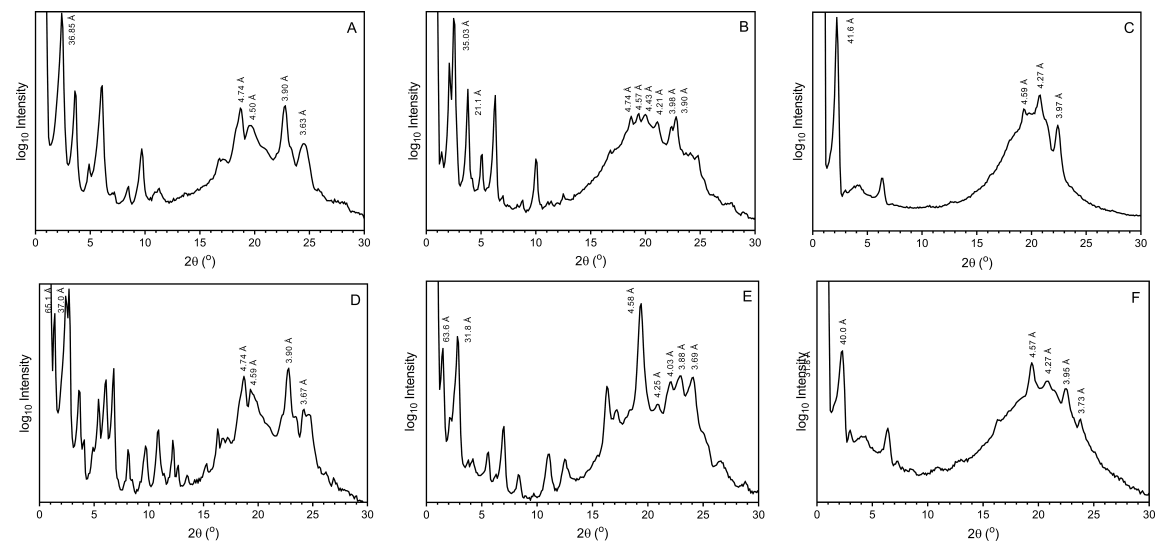

Figure 1- Small- and wide-angle powder X-ray diffraction spectra of (A) 100\% FKB after 4 days, (B) 50:50 blend of FKB:FPO after 4 days, (C) 100\% FPO after 4 days, (D) 100\% FKB after 12 days, (E) 50:50 blend of FKB:FPO after 12 days, and (F) 100\% FPO after 12 days storage at room temperature. 

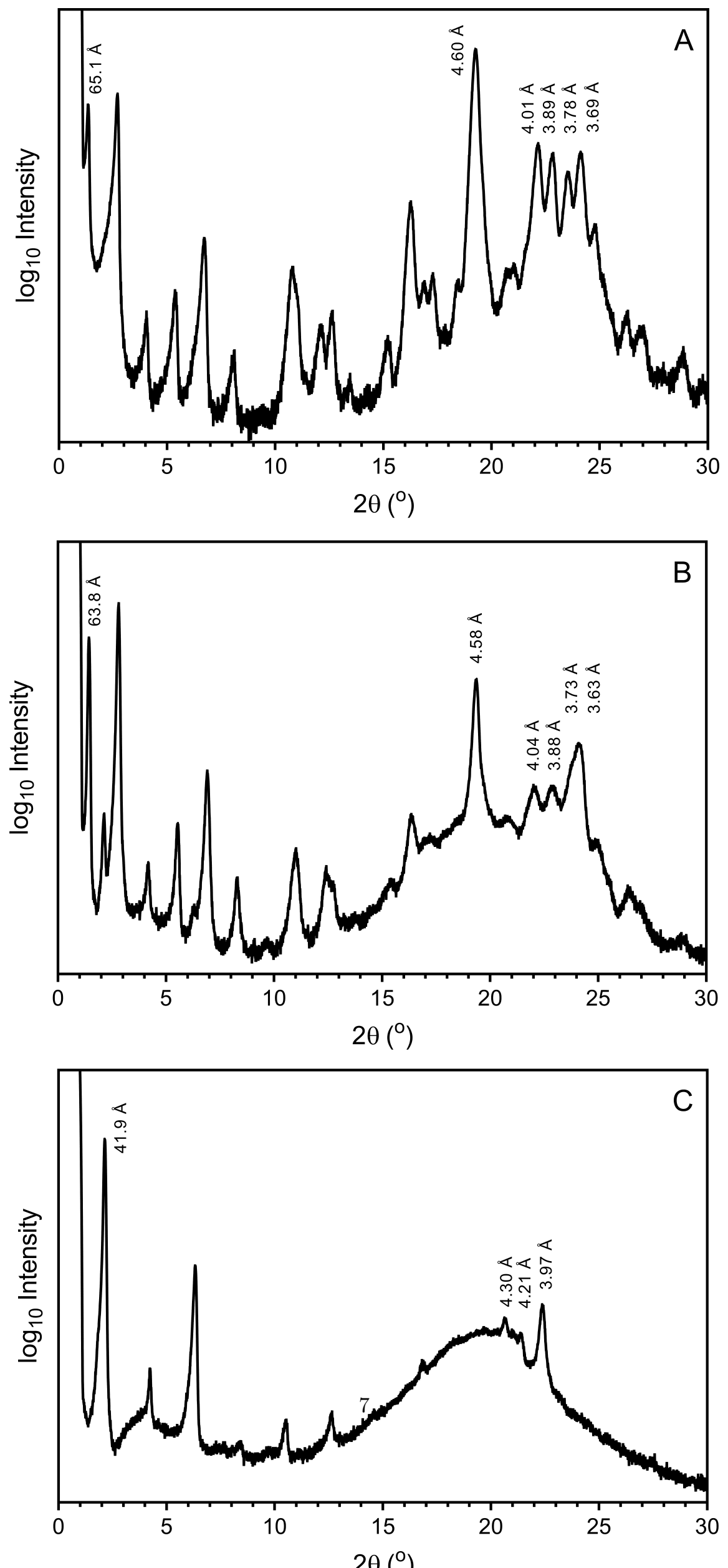
Figure 2- Small- and wide-angle powder X-ray diffraction spectra of (A) 100\% FKB after 60 days, (B) 50:50 blend of FKB:FPO after 60 days, and (C) 100\% FPO after 60 days storage at room temperature.

Melting profile

The thermal properties of fractionated pequi oil mixed with fractionated Kpangnan butter at different ratios and storage times at room temperature are shown in Table 4 and Fig.3. The X-ray diffraction analysis showed that after four days of static crystallization at room temperature, the crystal polymorphic transition was not complete except for fractionated 80:20 and 90:10 (\%w/w) pequi oil: fractionated Kpangnan butter, which had significantly higher melting points (Fig. 1). Since crystallization of the blends after four days of storage was not complete, different mixtures of metastable crystal forms were observed, making the interpretation of melting profiles difficult. However, after 12 days of storage, all blends were in the $\beta_{2}$ polymorphic form, with melting peaks between $32.6{ }^{\circ} \mathrm{C}$ to $42.1{ }^{\circ} \mathrm{C}$, which potentially made them a promising $\mathrm{CBE}$ for addition to $\mathrm{CB}$ to make chocolate. Moreover, blends containing $70 \%$ to $90 \%$ fractionated pequi oil could be directly used as a $100 \%$ cocoa butter alternative in compound chocolate formulations.

Table 4- Melting points $\left({ }^{\circ} \mathrm{C}\right)$ and enthalpies of fusion $(\mathrm{J} / \mathrm{g})$ for fractionated pequi oil (FPO) and fractionated Kpangnan butter (FKB) and their mixtures $(\mathrm{w} / \mathrm{w})$ after 4,12 , and 60 days of storage at $22^{\circ} \mathrm{C}$. Values represent the means and standard deviations of $n=2$ replicates.

\begin{tabular}{lllllll}
\hline FPO $(\%)$ & FKB $(\%)$ & Melting point $\left({ }^{\circ} \mathrm{C}\right)$ & Enthalpy $(\mathrm{J} / \mathrm{g})$ & Melting point $\left({ }^{\circ} \mathrm{C}\right)$ & Enthalpy $(\mathrm{J} / \mathrm{g})$ & Melting point $\left({ }^{\circ} \mathrm{C}\right)$ \\
\hline & & 4 days & 4 days & 12 days & 12 days & 60 days \\
0 & 100 & $38.20 \pm 0.91$ & $127.45 \pm 8.13$ & $38.40 \pm 0.42$ & $138.90 \pm 3.54$ & $42.82 \pm 0.08$ \\
10 & 90 & $39.90 \pm 1.47$ & $116.20 \pm 10.89$ & $43.14 \pm 0.20$ & $182.40 \pm 2.69$ & $43.01 \pm 0.17$ \\
20 & 80 & $37.14 \pm 0.14$ & $104.92 \pm 15.96$ & $41.98 \pm 0.38$ & $160.65 \pm 3.32$ & $42.00 \pm 0.11$ \\
30 & 70 & $41.89 \pm 0.04$ & $126.40 \pm 9.33$ & $41.76 \pm 0.28$ & $140.85 \pm 3.61$ & $41.02 \pm 0.41$ \\
40 & 60 & $34.84 \pm 0.05$ & $71.38 \pm 0.54$ & $40.05 \pm 0.13$ & $130.80 \pm 3.82$ & $40.03 \pm 0.28$ \\
50 & 50 & $33.52 \pm 0.50$ & $59.48 \pm 7.69$ & $38.35 \pm 0.18$ & $126.75 \pm 0.35$ & $37.92 \pm 0.18$ \\
60 & 40 & $32.19 \pm 0.49$ & $49.74 \pm 3.21$ & $36.50 \pm 0.47$ & $115.20 \pm 0.57$ & $35.88 \pm 0.12$ \\
70 & 30 & $30.89 \pm 0.62$ & $28.47 \pm 4.14$ & $33.44 \pm 0.36$ & $90.43 \pm 1.37$ & $34.27 \pm 0.32$ \\
80 & 20 & $33.32 \pm 0.11$ & $14.72 \pm 3.27$ & $32.91 \pm 0.28$ & $77.10 \pm 4.25$ & $32.67 \pm 0.22$ \\
90 & 10 & $31.59 \pm 0.42$ & $11.41 \pm 1.29$ & $32.61 \pm 0.18$ & $70.68 \pm 1.22$ & $31.99 \pm 1.15$ \\
100 & 0 & $29.59 \pm 0.27$ & $20.73 \pm 1.13$ & $29.52 \pm 0.66$ & $69.62 \pm 11.60$ & $28.93 \pm 0.58$ \\
\hline
\end{tabular}




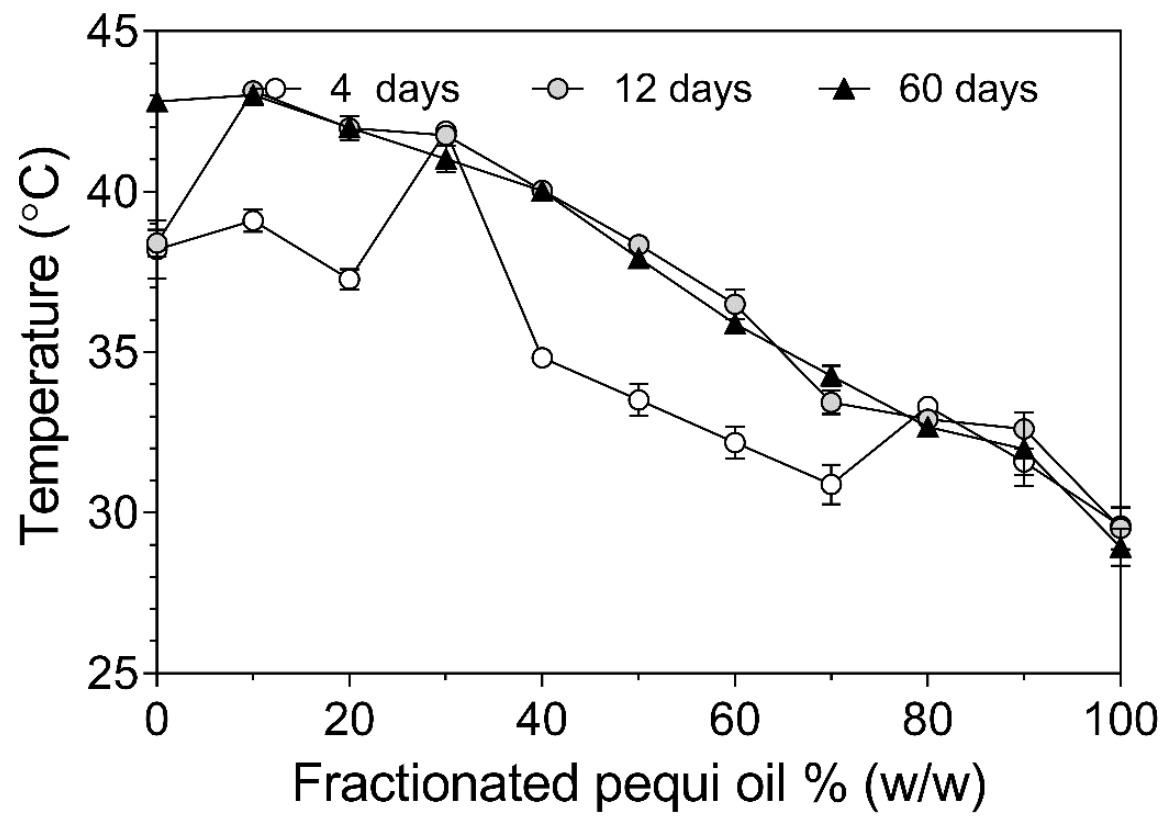

Figure 3- Peak melting temperature $\left({ }^{\circ} \mathrm{C}\right)$ of mixtures of fractionated pequi oil and fractionated Kpangnan butter at different proportions $(\mathrm{w} / \mathrm{w})$ after static crystallization in 4,12 , and 60 days of storage at room temperature $\left(22^{\circ} \mathrm{C}\right)$

Molecular composition and phase behavior

The TAG composition of fractionated pequi oil mixed with fractionated Kpangnan butter (w/w) is shown in Table 5. The main TAGs in $100 \%$ dry fractionated pequi oil were POP $(37 \%)$ and POO (21\%), while SOS (90\%) was the major TAG in 100\% solvent fractionated Kpangnan butter. Multi-step solvent fractionation was more efficient for increasing the amount of symmetrical TAG (SOS) in fractionated Kpangnan butter (increasing from $52 \%$ before fractionation to $90 \%$ after fractionation). In contrast, the single-step dry fractionation of pequi oil at $20^{\circ} \mathrm{C}$ only resulted in an increase in the amount of POP from $33.7 \%$ to $36.7 \%$ but did significantly decrease POO content from $38.7 \%$ to $21.9 \%$.

The amount of POS (the main TAG in cocoa butter) in all fractionated pequi oil-fractionated Kpangnan butter mixtures remained constant ( $5 \%$ ). While SOS was the main TAG in mixtures containing $10 \%$ to $70 \%$ fractionated pequi oil, POP was the major symmetrical TAG for the rest of the mixtures ( $80 \%$ and $90 \%$ ). van Malssen, Peschar, Brito \& Schenk (1996) showed that symmetrical mono-unsaturated triacylglycerols (POP, POS, and SOS) comprised $70 \%$ to $88 \%$ of total TAGs present in cocoa butter. In our study, we found the total amount of symmetrical TAGs only in fractionated blends containing $10 \%$ to $60 \%$ (w/w) fractionated pequi oil was in the range of total symmetrical TAGs of cocoa butter. The high melting point of binary blends containing $10 \%$ to $60 \%$ (w/w) fractionated pequi oilcan be explained by the high amount of SOS in these mixtures ( $84 \%$ to $43 \%$, respectively). These mixtures have a great potential to be categorized as cocoa butter improvers (CBIs). Cocoa butter mixed with CBIs had better heat resistance and bloom development properties at temperatures higher than ambient temperature (Lipp and Anklam,1998); Timms, 2003). For the binary mixtures containing $70 \%$ to $100 \%$ fractionated pequi oil, the high amount of low melting TAGs (OOO, POO, and SOO) resulted in a lower melting point at all storage times (4, 12, and 60 days).

Timms (2003) reported a blend of solvent fractionated palm oil and illipe butter was successfully used to produce cocoa butter equivalent (CBE). For the past 75 years, commercial CBEs in the market continue to be made in the same way, namely by blending palm mid-fraction (PMF) as a source of POP, with a high SOS fat such as shea butter, shea stearin, sal fat, or kokum butter (De Clercq, Kadivar, Van de Walle, De Pelsmaeker, Ghellynck \& Dewettinck, 2017). 
Table 5- The main triacylglycerol composition of fractionated pequi oil (FPO) and fractionated Kpangnan butter (FKB) and their mixtures (\%)

\begin{tabular}{lllllllll}
\hline & & & & & & & Total \\
FPO $(\%)$ & FKB $(\%)$ & OOO & POO & POP & SOO & POS & SOS & POP +1 \\
\hline 0 & 100 & $0.33 \pm 0.12$ & $0.30 \pm 0.05$ & nd & $2.63 \pm 0.33$ & $5.41 \pm 0.03$ & $89.65 \pm 0.49$ & 95.06 \\
10 & 90 & $0.38 \pm 0.04$ & $2.52 \pm 0.07$ & $4.29 \pm 0.06$ & $1.17 \pm 0.05$ & $5.16 \pm 0.06$ & $83.96 \pm 2.17$ & 93.43 \\
20 & 80 & $0.81 \pm 0.09$ & $4.13 \pm 0.01$ & $7.97 \pm 0.02$ & $1.20 \pm 0.00$ & $4.86 \pm 0.23$ & $75.48 \pm 0.11$ & 88.30 \\
30 & 70 & $1.04 \pm 0.01$ & $5.35 \pm 0.11$ & $11.52 \pm 0.04$ & $0.97 \pm 0.99$ & $4.97 \pm 0.09$ & $68.17 \pm 0.16$ & 84.65 \\
40 & 60 & $1.41 \pm 0.13$ & $7.57 \pm 0.07$ & $16.46 \pm 0.01$ & $0.85 \pm 0.19$ & $5.08 \pm 0.01$ & $61.55 \pm 0.45$ & 83.09 \\
50 & 50 & $1.79 \pm 0.09$ & $9.11 \pm 0.04$ & $20.23 \pm 0.07$ & $0.93 \pm 0.04$ & $4.88 \pm 0.09$ & $50.64 \pm 0.22$ & 75.74 \\
60 & 40 & $2.21 \pm 0.21$ & $11.02 \pm 0.02$ & $25.26 \pm 0.55$ & $0.94 \pm 0.02$ & $4.94 \pm 0.00$ & $42.75 \pm 0.16$ & 72.95 \\
70 & 30 & $2.77 \pm 0.19$ & $13.09 \pm 0.45$ & $28.02 \pm 0.74$ & $0.99 \pm 0.04$ & $4.62 \pm 0.18$ & $33.61 \pm 1.02$ & 66.24 \\
80 & 20 & $4.35 \pm 0.08$ & $18.51 \pm 0.45$ & $32.92 \pm 0.21$ & $1.19 \pm 0.04$ & $4.63 \pm 0.04$ & $21.05 \pm 0.04$ & 58.59 \\
90 & 10 & $4.33 \pm 0.13$ & $19.69 \pm 0.77$ & $36.13 \pm 1.09$ & $1.24 \pm 0.06$ & $4.17 \pm 0.14$ & $9.19 \pm 0.16$ & 49.49 \\
100 & 0 & $4.49 \pm 0.45$ & $21.91 \pm 0.93$ & $36.72 \pm 0.72$ & $1.37 \pm 0.08$ & $3.82 \pm 0.09$ & $0.70 \pm 0.02$ & 41.23 \\
\hline
\end{tabular}

nd: not detected

Based on Fig. 3, the melting point of binary mixtures containing $30 \%$ and $80 \%$ fractionated pequi oil showed an disproportionate increase in their melting point after four days of storage at room temperature. To better understand this phenomenon, the ternary phase diagram of POP+POS+SOS mixtures in metastable polymorphic form (pseudo- $\beta$ ') (Ghazani \& Marangoni, 2021) was used to pinpoint the location of these mixtures in the ternary plot (Fig. 4). The area with the symbols of * and + show the location of mixtures containing $30 \%$ and $80 \%$ fractionated pequi oil, respectively.

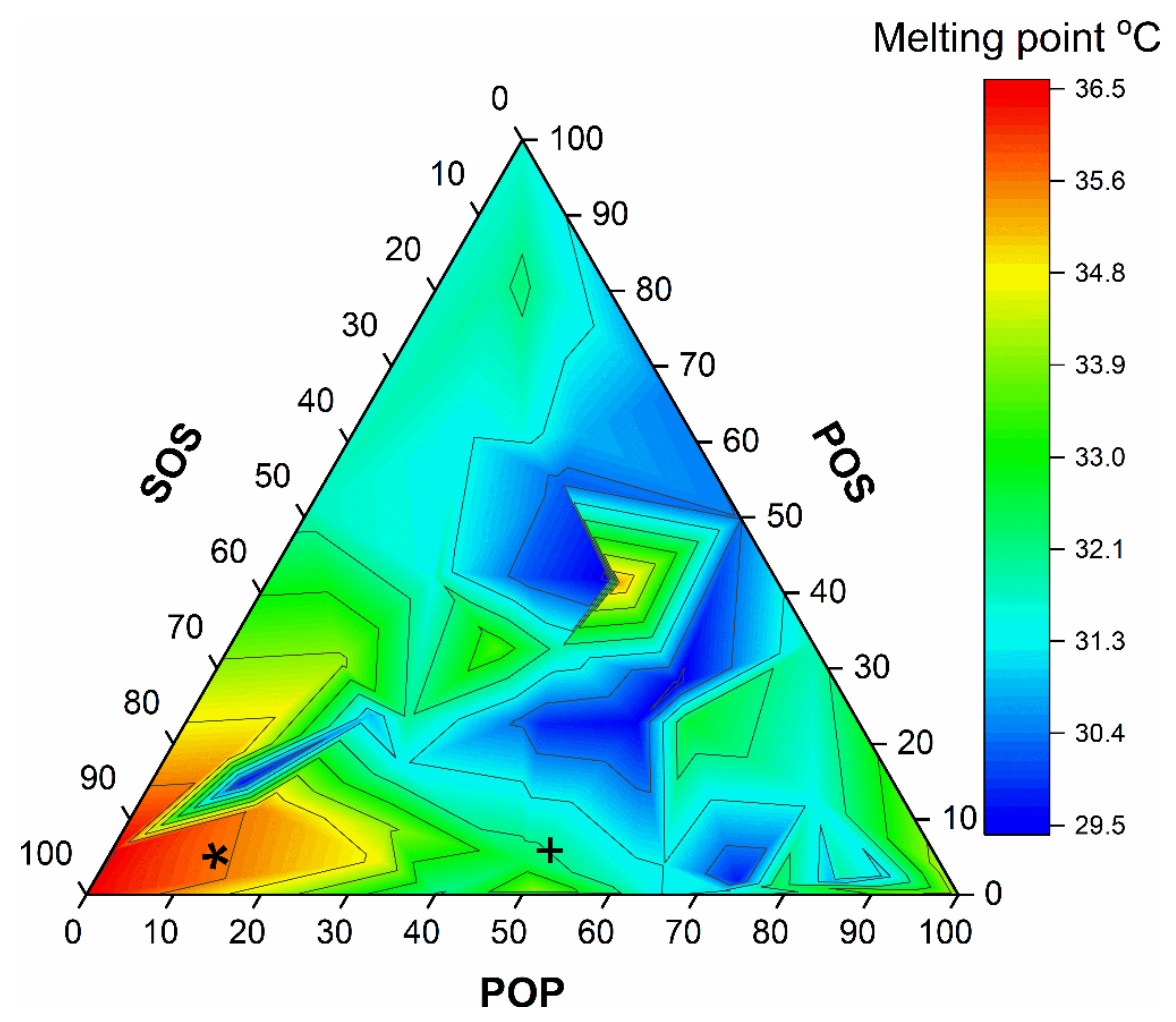


Figure 4- Ternary melting phase diagram of static crystallized POP $+\mathrm{POS}+\mathrm{SOS}$ in pseudo- $\beta$ ' crystal polymorphic form (adapted from Ghazani \& Marangoni, 2021). The symbols * and + represents the amount of POP, POS and SOS in $30 \%$ and $80 \%$ FPO after normalizing, respectively.

Lipp, Simoneau, Ulberth, Anklam, Crews, Brereton, .. \& \& Wiedmaier, (2001) showed that commercial CBEs generally contain a lower amount of POS, the same amount of SOS, and a higher amount of POP than CB. In our previous study (Ghazani \& Marangoni, 2018), we reported the main TAG profile of CB as POP 15\%, POS $39 \%$, and SOS $28 \%$. Binary mixtures containing $70 \%$ fractionated pequi oil, and $30 \%$ fractionated Kpangnan butter had a TAG composition of $28 \%$ POP (higher than POP amount in CB), $4.6 \%$ POS (lower than POS amount in CB), and 33\% SOS (equal amount than CB). This mixture displayed melting points of 33 and $34^{\circ} \mathrm{C}$ after 12 and 60 day storage, respectively, and crystallized into a stable triclinic $\beta_{2}$ form after 12 days at $22^{\circ} \mathrm{C}$. This particular binary mixture displayed the most desirable solid-state characteristics and had potential for being used as a commercial CBE.

\section{CONCLUSION}

A limited and shrinking supply for CB, combined with an increased demand, has forced the food industry to look for alternatives to CB to manufacture chocolate and confectionery products. Even though palm kernel oil and hydrogenated palm oil fractions can be used a cocoa butter equivalents and replacers, the current concerns about sustainability have made these ingredients less desirable. In this study, we have shown that it is possible to produce functional CBEs containing no palm oil products from fractionated Kpangnan butter and fractionated Pequi oil. The melting point and crystal structure of the selected binary mixture containing $70 \%$ fractionated Pequi and 30\% Kpangnan butter suggest potential for this mixture as a commercial CBE.

\section{REFERENCES}

Adomako D. Fatty acid composition and characteristics of Pentadesma butyracea fat extracted from Ghana seeds. J. Sci. Food Agric. 1977;28:384-6.

Austin KG, Mosnier A, Pirker J, McCallum I, Fritz S, Kasibhatla PS. Shifting patterns of oil palm driven deforestation in Indonesia and implications for zero-deforestation commitments. Land use policy. 2017;69:418 .

Ayegnon BP., Kayodé AP., Tchobo FP, Azokpota P, Soumanou MM, Hounhouigan DJ. Profiling the quality characteristics of the butter of Pentadesma butyracea with reference to shea butter. J. Sci. Food Agric. 2015;95:3137-3143.

Carlson KM, Heilmayr R, Gibbs HK, Noojipady P, Burns DN, Morton DC, Walker NF, Paoli GD, Kremen C. Effect of oil palm sustainability certification on deforestation and fire in Indonesia. PNAS. 2018;115:121-126.

Christie WW. A simple procedure for rapid transmethylation of glycerolipids and cholesteryl esters. J. lipid res. 1982;23:1072-1075.

De Clercq N, Kadivar S, Van de Walle D, De Pelsmaeker S, Ghellynck X, Dewettinck K. Functionality of cocoa butter equivalents in chocolate products. Eur. Food Res. Technol. 2017;243:309-321.

Dencausse L, Ntsourankoua H, Artaud J, Clamou JL. Comparaison des compositions lipidiques des beurres de pentadesma et de karité. OCL. Oléagineux, corps gras, lipides. 1995;2:143-147.

Faria-Machado AF, Tres A, van Ruth SM, Antoniassi R, Junqueira NT, Lopes PSN, Bizzo HR. Discrimination of pulp oil and kernel oil from pequi (Caryocar brasiliense) by fatty acid methyl esters fingerprinting, using GC-FID and multivariate analysis. J. Agric. Food Chem. 2015;63:10064-10069.

Ghazani SM, Marangoni AG. The ternary solid state phase behavior of triclinic POP, POS, and SOS and its relationship to CB and CBE properties. Cryst. Growth Des. 2018;19:704-713.

Ghazani SM, Marangoni AG. Molecular Origins of Polymorphism in Cocoa Butter. Annu. Rev. Food Sci. Technol. 2021;12:567-590. 
Guedes AMM, Antoniassi R, de Faria-Machado AF. Pequi: a Brazilian fruit with potential uses for the fat industry. OCL. 2017;24:D507.

Guedes AMM, Antoniassi R, Galdeano MC, Grimaldi R, de Carvalho MG, Wilhelm AE, Marangoni AG. Length-scale specific crystalline structural changes induced by molecular randomization of pequi oil. J. Oleo Sci. 2017;66:469-478.

Lipp EM, Anklam E. Review of cocoa butter and alternative fats for use in chocolate-part A. Compositional data. Food chem.1998;62:73-97.

Lipp M, Simoneau C, Ulberth F, Anklam E, Crews C, Brereton P, ... Wiedmaier C. Composition of genuine cocoa butter and cocoa butter equivalents. J Food Compost Anal. 2001;14:399-408.

Salas JJ, Bootello MA, Martínez-Force E, Garcés R. Tropical vegetable fats and butters: properties and new alternatives. Ol. corps gras lipides. 2009;16:254-258.

Sato K, Arishima T, Wang ZH, Ojima K, Sagi N, Mori H. Polymorphism of POP and SOS. I. Occurrence and polymorphic transformation. JAOCS. 1989;66:664-674.

Sato K, Ueno S, Yano J. Molecular interactions and kinetic properties of fats. Prog. Lipid Res. 1999;38:91-116.

Tchobo, FP, Natta AK, Barea B, Barouh N, Piombo G, Pina M, et al., Sohounhloue D. C. Characterization of Pentadesma butyracea Sabine butters of different production regions in Benin. JAOCS. 2007;84:755-760.

Timms RE. Production and characteristic properties. In; Confectionery fats handbook: properties, production and application. The Oily Press; 2003. p.191-254.

van Malssen K, Peschar R, Brito C, Schenk H. Real-time X-ray powder diffraction investigations on cocoa butter. III. Direct $\beta$-crystallization of cocoa butter: Occurrence of a memory effect. JAOCS. 1996;73:12251230.

Vieira RF, Martins MV. Recursos genéticos de plantas medicinais do cerrado: uma compilação de dados. Rev. Bras. de Plantas Medicinais. 2000;3:13-36.

Wang ZH, Sato K, Sagi N, Izumi T, Mori H. Polymorphism of 1, 3-di (saturated acyl)-2-oleoylglycerols: POP, SOS, AOA and BOB. Journal of Japan Oil Chemists' Society. 1987;36:671-679.
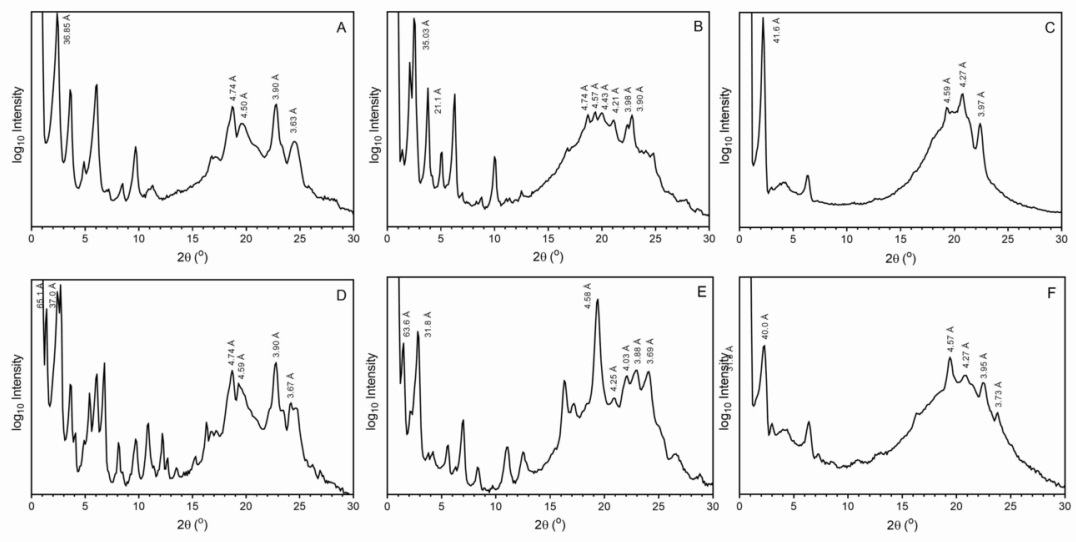

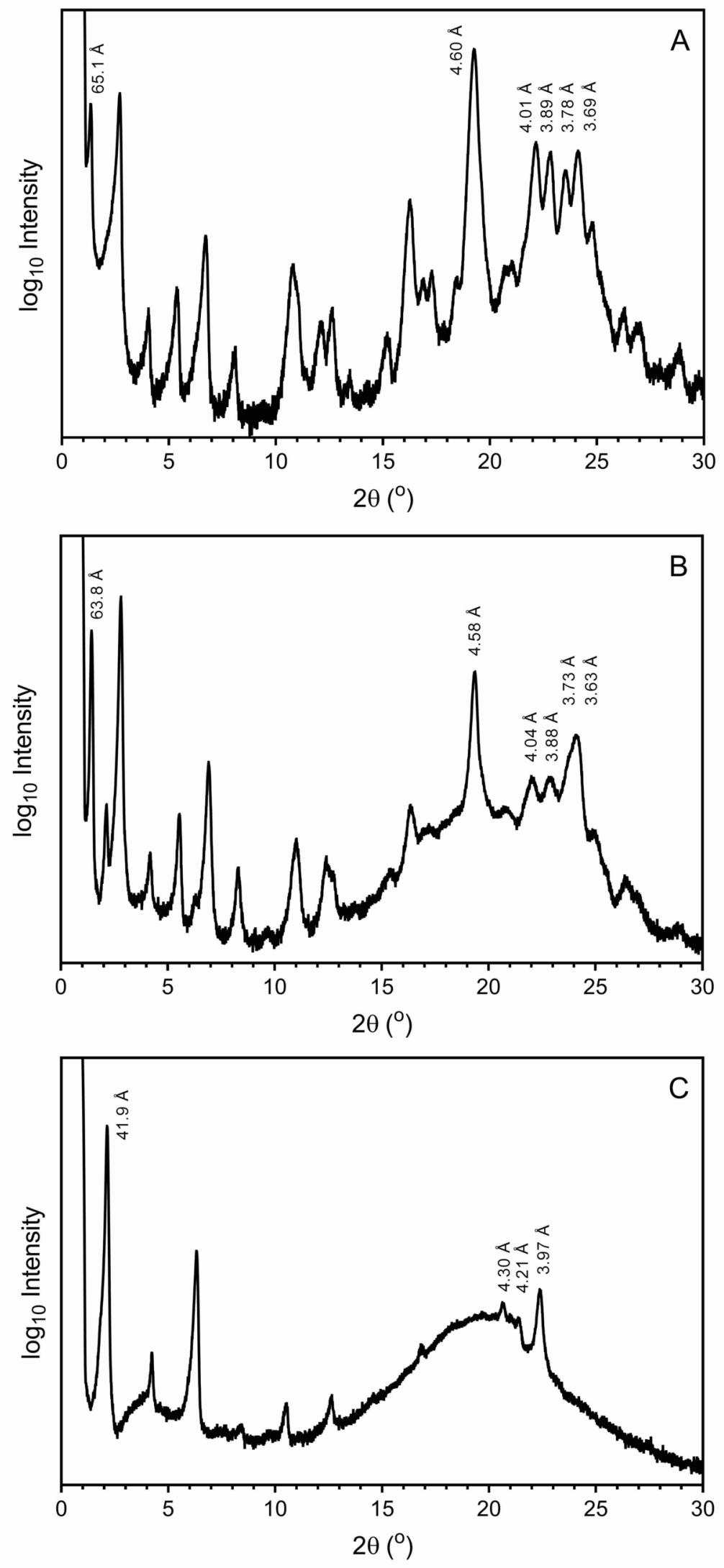

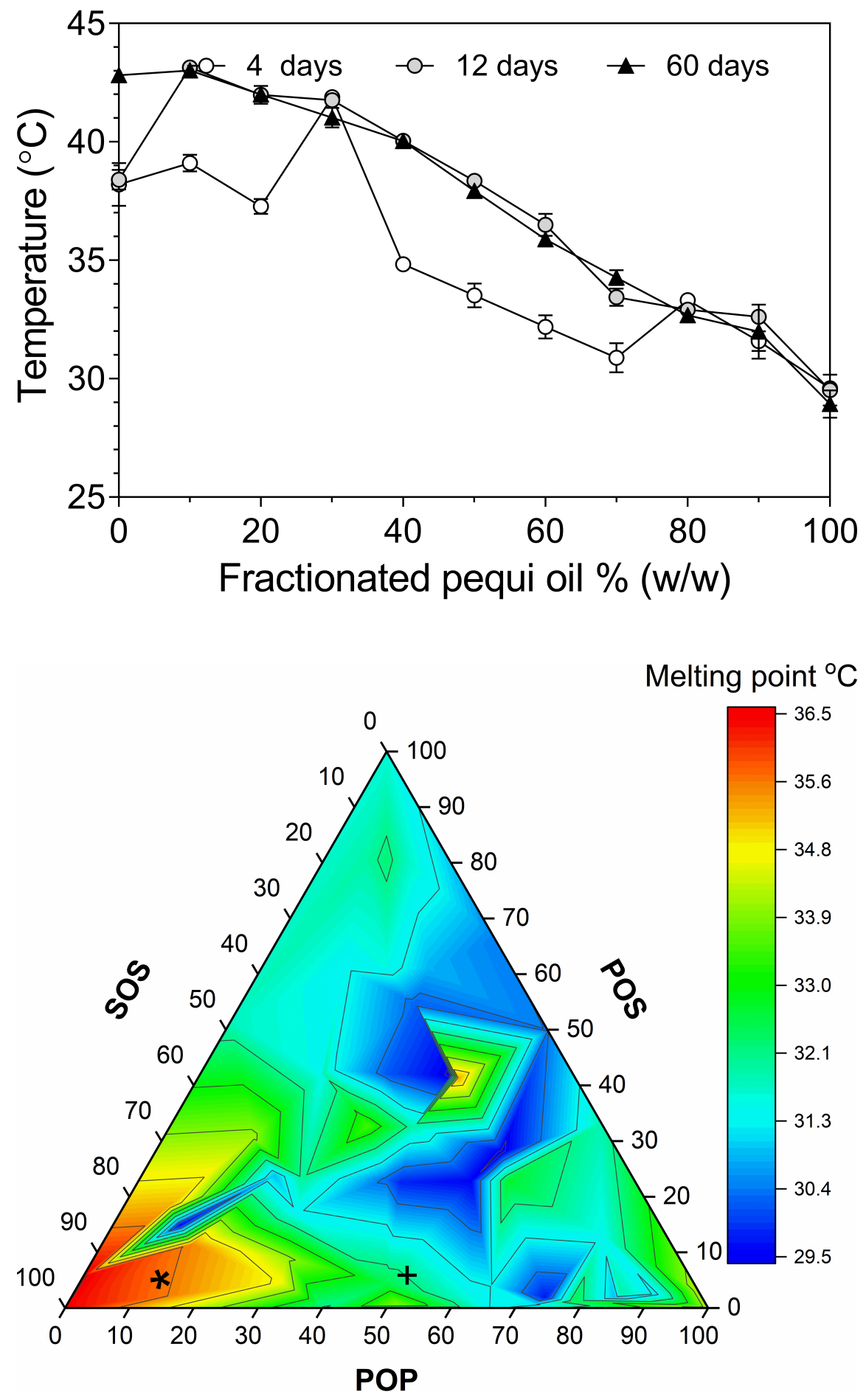